\title{
A inserção do Projeto Vale das Experiências na dinâmica socioeconômica, ambiental e cultural de desenvolvimento do Vale do Paranhana
}

Alvaro Luis de Melo Machado ${ }^{1}$

\section{Resumo}

Este artigo apresenta alguns resultados de uma pesquisa realizada na região Vale do Paranhana com o objetivo de identificar e descrever algumas potencialidades e oportunidades turísticas locais. Apresentam-se, também, subsídios teórico-metodológicos territoriais para serem utilizados no estudo das atuais dinâmicas socioeconômicas e nas ações e políticas de desenvolvimento regional. O aproveitamento do espaço rural e natural tem contribuído para o enriquecimento da oferta de alternativas e oportunidades. O turismo tem buscado novos espaços que possibilitem a formatação de produtos diferenciados como potencialidades locais. Os resultados refletem algumas possibilidades paisagísticas diferenciadas, as relações sociais desenvolvidas, a presença de manifestações culturais, a existência de fauna e flora expressivas e a relação das ações antrópicas e a tentativa de formatação de um produto que valorize a ideia de inserção do turista no lugar onde a atividade é desenvolvida.

Palavras-chave: Desenvolvimento regional. Turismo local. Vale das Experiências.

\section{Abstract}

This article presents some results of a survey conducted in the region Paranhana Valley with the objective of identify and describe some potentialities and opportunities of the local tourism. Are presented also territorial theoretical and methodological subsidies for use in the study of current socioeconomic dynamics and in the actions and policies of regional development. The use of rural and natural space has contributed for the enrichment of alternatives and opportunities supply. Tourism has searched new spaces that enable formatting of differentiated products as local potentialities. The results reflect some landscaping differentiated possibilities, social relations developed, the presence of

\footnotetext{
${ }_{1}^{1}$ Professor e Coordenador do Curso de Turismo das Faculdades Integradas de Taquara - Faccat - Taquara (RS). Mestre em Turismo. alvaromm@faccat.br
} 
cultural manifestations, the existence of expressive flora and fauna and the relation of anthropic actions and attempt to format a product that valorizes the idea of insertion of the tourist in the place where the activity is developed.

Keywords: Regional development. Local tourism. Valley of the Experiences.

\section{Introdução}

No estudo do desenvolvimento de uma região ou de um território, é necessário pensá-lo como um sistema que sofre influência de variáveis internas (participação, ambiental, social, econômica e a cultural) e que interage com os sistemas territoriais de maior escala. Sob o ponto de vista econômico, as ações devem ter como objetivo a implantação e gestão de projetos potencializadores da economia local, visando à geração de ocupação e renda, a criação ou fortalecimento de micro, pequenas e médias empresas e/ou a implementação de estratégias de integração competitiva no mercado global (MORAES, 2008).

A construção de um sistema local autônomo e mais integrado nas redes globais pode ser uma estratégia de desenvolvimento regional. Para isso, o Estado e os agentes econômicos devem atuar como atores fundamentais em programas para o aumento de postos de trabalho e geração de renda, para a redução da pobreza e a reinserção social de segmentos marginalizados e/ou de trabalhadores pouco qualificados para as novas atividades. Isso se poderá verificar pelos resultados dos empreendimentos e da gestão dos seus fatores, atuais e potenciais, assim como a partir da velocidade de incorporação de conhecimentos e de transformação de possibilidades externas em oportunidades internas, de modo a solucionar problemas ou atender às necessidades do território como um todo.

O turismo, na tentativa de atratividade constante e variada, tem buscado novos espaços que possibilitem a formatação de produtos diferenciados para serem agregados às atrações já existentes, ou indicar novos destinos à sua oferta habitual a fim de responder às novas tendências das demandas dos turistas.

O aproveitamento do espaço rural e do natural ainda conservado, com suas características próprias e peculiares, tem contribuído para o enriquecimento da oferta de alternativas e oportunidades nos âmbitos local, nacional e internacional. Tal produto parece refletir as possibilidades paisagísticas diferenciadas, as relações sociais desenvolvidas, a presença de manifestações culturais, a existência de fauna e flora expressivas e a relação das ações antrópicas, inseridas em tais espaços, na formatação de um produto que valorize a ideia de inserção do turista no lugar onde a atividade é desenvolvida.

O processo de busca da identidade turística local tem demonstrado não ser uma tarefa fácil. A variedade de produtos, as diferenças locais e a vulnerabilidade das comunidades tradicionais podem representar impactos ambientais e culturais, de diferentes magnitudes. Porém tais processos buscam, em comum, conduzir ações que viabilizem produtos capazes de atender a públicos específicos, possibilitar novas atividades econômicas que revertam em acréscimo de renda local, em diversificação da oferta de serviços 
especializados e na incorporação de novos territórios na atividade turística.

Configuram-se, assim, processos cosmopolitas paradoxais, pois, ao mesmo tempo em que se padronizam as culturas e se uniformiza a história, estimula-se a regionalização, por meio de nova valorização do espaço local, rural e urbano, resultante da possibilidade de diferenciação diante de outros lugares. Dessa forma, o nível de organização regional passa a ser um dos principais critérios de delimitação territorial, especialmente na possibilidade de organização turística focada no território.

\section{As comunidades regionais e o desenvolvimento local}

O que parece ser um dos caminhos mais adequados para estruturar o planejamento e o desenvolvimento regional é a ideia de organização local, baseada nas comunidades, instituições e atores locais. Para Maldonado (2010, p. 28), entender a natureza de uma comunidade local significa "[...] definir os princípios, valores, normas e instituições que regem a forma de organização e convivência de um determinado grupo humano, que por sua vez os diferencia de outros atores da sociedade". Para o autor, a identidade da comunidade poderia também ser expressa pelo enraizamento da consciência "[...] de pertencer a um determinado grupo étnico" (loc. cit.), podendo expandir-se para um sentimento de pertencimento a um determinado local, território ou região.

O território é resultante da relação da sociedade com o espaço, quando nele se incorporam as relações econômicas e de produção daquela. Para que se tenha um território, é necessário que a sociedade ou os grupos sociais apropriem-se do espaço físico, ampliem e utilizem as inovações tecnológicas e que exista um sentimento de "pertencimento", ou seja, a identificação histórica da sociedade com o seu território.

Assim, analisar o conceito de comunidade regional exclusivamente com a ideia de pertencimento étnico impediria novos olhares para a formação de produtos e atividades de turismo comunitário. Esses não estariam diretamente associados a características étnicas particulares ou singulares, mas focados em uma ideia de pertencimento coletivo a um território ou a um local. Essas novas abordagens entendem o espaço turístico é o resultado da associação entre o produto da ação ou da atividade antrópica com determinada paisagem, ou seja, a utilização social e cultural do ambiente. Esse uso poderá influenciar e definir os processos de desenvolvimento regional e a produção, configuração e delimitação espacial e territorial.

É importante entender como se processa a relação de territorialidade com a organização pública do turismo, identificada especialmente na determinação dos espaços turísticos regionalizados. O Estado do Rio Grande do Sul afirmou sua opção pelo planejamento turístico regionalizado quando da realização da Conferência Estadual do Turismo, organizada pela Secretaria de Turismo do Estado no ano de 2011. Partindo da reflexão da antiga divisão territorial e, como resultado das discussões travadas nas conferências regionais, realizadas em cada uma das 11 regiões turísticas, englobando a totalidade de suas microrregiões, foi identificado que "[...] cada microrregião possuía níveis de governança e de desenvolvimento turístico distintos. Além disso, cada microrregião possuía um coordenador responsável pela condução das ações no local" (RIO GRANDE DO SUL, 2012, p. 30). 
A partir de tais discussões, surgiu a necessidade de "[...]uma ação específica de revisão da regionalização turística do estado, buscando formas de empoderamento destas importantes instâncias de governança, adequação das atuais microrregiões e inclusão de novos municípios" (RIO GRANDE DO SUL, 2012, p. 30). Alinhada a tais discussões, a microrregião do Vale do Paranhana, anteriormente alinhada à Região Serra Gaúcha, define sua estratégia de organização baseada na concepção de seu espaço turístico associado ao produto da relação de suas comunidades com determinadas paisagens e da utilização social e cultural de tal ambiente, que pode, assim, definir a configuração e a delimitação espacial.

O espaço assume, então, significado especial, quando se apresenta como "lugar de animação", de trocas de bens e de símbolos, de difusão de ideias, remetendo ao entendimento da necessidade constante de interações sociais que possam "[...] favorecer processos de crescimento e mudança" (ALBAGLI; MACIEL, 2003, p. 423). É nessa percepção do espaço que a ação da governança local tem seu foco, integrada e alinhada com a política estadual de turismo, promovendo relações entre os poderes públicos locais, empresários e comunidades.

A ideia de organização turística baseada na região surge, portanto, da necessidade de intervenção em uma determinada unidade espacial. Além disso, é importante entender que "[...] dificilmente, encontram-se regiões totalmente homogêneas" (FEGER et al., 2008, p. 8), já que se envolvem municípios com diferentes níveis de preparação e de potencialidades.

É importante a compreensão de que, com o acréscimo do turismo e de sua presença constante nas ações de planejamento dos territórios, as comunidades compreendem a importância de inserção em um mercado altamente disputado e profissional. As pressões por qualificação, organização regional e propostas inovadoras identificam o turismo como um forte elemento de pressão sobre comunidades rurais, paisagens naturais e singularidades locais, particularmente difíceis de serem solucionadas por pequenos empreendedores, quando atuando de forma isolada. Alia-se a tais questões a grande dificuldade em acessar os mercados turísticos emissivos, promovendo de forma adequada os destinos e produtos turísticos.

Tais questões são mais bem identificadas quando da percepção da falta de acessos, sinalização adequada, qualificação de pessoal, promoção de produtos e destinos e relações com o mercado, propiciando uma fraca competitividade aos empreendedores e uma dificuldade de promoção turística do destino como todo.

Cabe, assim, à instância de governança local valorizar os espaços por meio da organização das identidades regionais e da promoção da diferenciação diante de outros lugares. Tais ações poderão incluir a definição de produtos, promoção, organização, qualificação e desenvolvimento integrado. Surge dessa forma o Projeto Vale das Experiências, como uma proposta integrada de organização regional para o desenvolvimento turístico do Vale do Paranhana.

Na tentativa de compreender as relações desenvolvidas na formatação do planejamento regional, define-se como objetivo do presente artigo analisar as políticas de organização regional do Vale do Paranhana baseadas no planejamento, capacitação e organização do Projeto Vale das Experiências. 
O método de pesquisa, de natureza qualitativa e exploratória, com base em revisão bibliográfica, compreendeu a abordagem conceitual do Turismo de Experiência. Este está inserido em um determinado espaço e compartilhado pelos atores do turismo regional, no desempenho de seu papel como aglutinadores no ordenamento da atividade turística. Além disso, o método abrangeu pesquisa de revisão das etapas desenvolvidas pelo projeto, identificando ações e programas focados em um determinado processo de organização turística regional.

\section{O Território como referência para as políticas de desenvolvimento}

A abordagem territorial do desenvolvimento pode ser um instrumento útil para as políticas públicas ou uma forma de ação dentro do território, valorizando os atributos socioeconômicos, ambientais e culturais das comunidades e dos atores sociais. Dessa forma, o território passaria a ser interpretado como uma unidade de referência e de mediação para as ações e para as políticas públicas de desenvolvimento territorial.

Para que seja constituído um território, é necessário que a sociedade (ou os grupos sociais) aproprie-se do espaço físico, amplie a utilização das inovações tecnológicas e exista um sentimento de pertencimento ou de identificação da sociedade com o seu território. A sua legitimação passa pelo discurso e pela negociação em relação à história, à política, à ciência, ao mercado e às relações sociais. A territorialidade está relacionada à presença de condições ou de situações que indiquem a existência de um território.

O desenvolvimento territorial está relacionado ao uso efetivo da capacidade, da competência e da habilidade das comunidades locais, tanto urbanas como rurais, e à identidade social e histórica própria do território. Isso se poderá verificar pelos resultados dos empreendimentos e da gestão dos seus fatores, atuais e potenciais, assim como por meio da velocidade de incorporação de conhecimentos e de transformação de possibilidades externas em oportunidades internas, de modo a solucionar problemas ou atender a necessidades do território como um todo.

O desenvolvimento territorial pode ser considerado um modelo com características endógenas porque se baseia na capacidade das comunidades e organizações locais, urbanas e rurais para criarem estratégias de desenvolvimento e para praticarem a solidariedade e a participação. Além dessas origens, o desenvolvimento territorial pode ter outras raízes igualmente endógenas nos casos em que as comunidades se mobilizam em torno de programas e de processos permanentes de organização de capacidades, competências e habilidades dos atores sociais locais. Assim, surgem a noção alternativa e a abordagem do desenvolvimento territorial, quando essa última se torna um modo de ação que valoriza os atributos políticos e culturais das comunidades e dos atores sociais e o território passa a ser interpretado como uma nova unidade de referência e mediação das ações do Estado.

O conceito de desenvolvimento territorial pode incluir as abordagens teóricas de crescimento econômico endógeno, segundo as quais a inovação tecnológica também passa a ser considerada um fator endógeno na função de produção. De acordo com Vázquez-Barquero (2001), os fatores determinantes do desenvolvimento econômico 
endógeno são as inovações e a difusão tecnológica (nos sistemas produtivos), a organização flexível da produção, a geração de economias de aglomeração e de diversidade, além do fortalecimento das instituições (aumento da flexibilidade e da complexidade institucional).

Dessa forma, os processos de difusão de inovações e de conhecimentos poderiam transformar e renovar o sistema produtivo, impulsionando o desenvolvimento econômico e a dinâmica produtiva. Esses processos são consequências da estrutura empresarial e institucional e da ação dos agentes econômicos e atores sociais. Essa interpretação "[...] trabalha com a ideia de que a política de desenvolvimento local é capaz de viabilizar, de forma eficiente, uma resposta local aos desafios da globalização" e as abordagens do desenvolvimento territorial se transformam em um instrumento de ação (VÁZQUEZ-BARQUERO, 2001).

Além disso, o desenvolvimento territorial está diretamente ligado às características da organização social e ao nível das relações institucionais e de confiança entre os atores encontrados em cada região ou território. Essas relações, quando existentes, estão agrupadas sob a denominação de capital social.

A expressão capital social é uma noção teórica de utilização relativamente recente nas pautas dos governos, organizações não-governamentais (ONGs) e organismos internacionais. A importância do capital social verifica-se na presença e na qualidade das relações sociais para o desencadeamento do processo de desenvolvimento. O capital social forma-se a partir de relações sociais existentes entre a sociedade civil e as suas organizações (associação de produtores de leite e cooperativas) e o Estado com o objetivo de realizar ações conjuntas. Além disso, o capital social também é proveniente das relações sociais estabelecidas com grupos socioeconômicos externos à região, permitindo a realização de trocas com os mercados e o acesso externo a informações e a conhecimentos. Outro fator gerador de capital social diz respeito às relações sociais endógenas ou locais que se referem à capacidade dos atores sociais locais para gerar relações sociais baseadas na reciprocidade, na confiança e no seu potencial organizativo.

Dessa forma, a noção teórica de capital social permite várias possibilidades de investigação das contribuições desse capital para o desenvolvimento, quando os seus vários tipos e dimensões são dependentes e possuem um caráter dinâmico (MORAES, 2008). Assim, espera-se que o capital social existente no território objeto deste estudo, a região administrativa do Vale do Paranhana, articulado com instituições externas, possa contribuir positivamente para o desenvolvimento do turismo nesse território.

Para este estudo, definiu-se que o conceito mais apropriado e mais próximo de outras definições sobre o tema é o de desenvolvimento territorial rural como o ambiente onde os territórios rurais conseguem desenvolver suas potencialidades e, ao mesmo tempo, aproveitar as oportunidades externas de diversos tipos e formas. Assim, constituiria uma dinâmica socioeconômica local diferenciada de desenvolvimento rural.

\section{Dinâmicas de desenvolvimento dos territórios rurais}

Após a segunda guerra mundial, as áreas rurais dos países com capitalismo mais 
avançado foram sendo estruturadas com base em um modelo de desenvolvimento da agricultura que ficou conhecido como modernização agrícola. Esse modelo caracterizou-se pela integração e pela funcionalidade da agricultura ao modo de desenvolvimento fordista do sistema econômico capitalista, no qual o rural era considerado sinônimo de agrícola, podendo, por isso, ser denominado de rural-agrícola. Por essa razão, a agricultura modernizada foi se caracterizando por dois processos contraditórios, um progressivo declínio do seu peso na participação da economia nacional e outro de integração da agricultura dentro do sistema produtivo industrial global, seguindo um modelo fordista. Assim, a agricultura produtivista do período fordista passou a ser orientada exclusivamente para o crescimento da produtividade, da escala e da padronização do produto. No Brasil, a modernização da agricultura - na qual o rural-agrícola cumpriu o seu papel funcional de fornecimento de trabalhadores, alimentos, matérias-primas, divisas e outros recursos para o setor urbano-industrial - provocou um grande fluxo de população rural em direção aos centros urbanos, fugindo da pobreza em da falta de alternativas de renda e emprego nas áreas rurais. Esse processo de migração rural-urbana gerou uma favelização dos grandes centros urbanos, uma vez que o setor industrial-urbano não teve capacidade para absorver todo o excedente de população rural.

Então, se, no período de modernização, os sinais de bem-estar indicavam para o progresso industrial e para a vida nas cidades, agora, com a crise da modernização, já se verifica uma maior valorização dos aspectos ligados à organização social das áreas rurais, embora os níveis de desenvolvimento socioeconômico de muitos territórios rurais permaneçam ainda muito baixos. Essa revalorização do local, a capacidade de organização e de pressão dos atores sociais e os resultados das políticas públicas reforçam a existência do território rural. No debate brasileiro dos últimos anos em torno do desenvolvimento rural, da mesma forma como já se fazia na Europa desde o final da década de 1970, verifica-se uma mudança de visão sobre as novas abordagens utilizadas para compreender o papel do rural no desenvolvimento regional do país.

Essas perspectivas vêm substituindo a visão tradicional, baseada na dicotomia rural-urbana, que, por um lado, ainda relaciona o rural com atraso e o interpreta como sinônimo de agrícola e, por outro, vê o urbano como moderno, industrial e de serviços. A nova perspectiva sobre o mundo rural se apoia em argumentos que abrem a possibilidade de o território rural oferecer alternativas de emprego e renda e diversas outras formas de melhoria na qualidade de vida da sua população. No entanto, para oferecer isso, o território rural tem que utilizar o seu potencial local e aproveitar as suas características históricas e culturais particulares e, também, estar integrado socioeconomicamente com o seu entorno e com o exterior. Esses são os contornos que poderão levar a uma nova ruralidade e contribuir para o desenvolvimento local de territórios rurais como a região Vale do Paranhana.

Para Abramovay (2000), não existe qualquer razão para que o conceito de meio rural seja associado à ideia de um declínio ao longo do tempo, mesmo considerando uma real e significativa redução histórica do peso da produção agrícola na maioria das economias nacionais. As dinâmicas de algumas regiões rurais, principalmente em função dos menores custos de reprodução da força de trabalho e da proximidade resultante da expansão da infraestrutura de transportes e comunicações, demonstram que a rurali- 
dade não impede a geração de empregos. Do mesmo modo, muitas vezes, também a baixa densidade populacional e as distâncias não são obstáculos ao desenvolvimento. Muitas regiões rurais europeias estão inseridas em algumas das zonas mais dinâmicas, no interior de alguns países, ajudando na geração de novos empregos. Para as regiões rurais que ainda estão procurando o seu caminho para o desenvolvimento, as dinâmicas socioeconômicas de desenvolvimento de outras regiões rurais mais prósperas podem representar modelos alternativos de trajetórias de desenvolvimento para elas, embora se reconheça a diversidade e a importância das características locais de cada território.

Este estudo fundamenta-se no pressuposto generalizado, neste início de século $\mathrm{XXI}$, entre os principais investigadores dos processos de desenvolvimento, tanto no Brasil como na Europa, que a influência do rural é essencial para a compreensão da diversidade e das origens dos processos de desenvolvimento dos territórios e da sua reprodução. Até mesmo nos ambientes mais urbanos, verificam-se traços rurais, uma vez que as relações rurais-urbanas aprofundaram-se sem que esses dois espaços perdessem suas principais características.

Portanto, nos territórios rurais, a agricultura deixa de ser central na economia do território. Além disso, as atividades produtivas agrícolas, industriais e de serviços passam a coexistir internamente. Como consequência do declínio da importância da agricultura modernizada "fordista", esta vai se tornando multifuncional, e o território rural começa a ser caracterizado pela diferenciação produtiva e por um processo de integração territorial dos setores, com uma interrupção do fluxo migratório em direção aos centros urbanos (BASILE; CECCHI, 2001).

\section{A perspectiva territorial do desenvolvimento rural}

O desenvolvimento rural pode ser considerado como um processo de mudança social com o objetivo de promover ações articuladas, locais e endógenas, nos territórios rurais. Dessa forma, o território passaria a ser interpretado como uma nova unidade de referência e mediação para as ações e políticas públicas de desenvolvimento rural.

Atualmente, no Brasil, um tema que vem sendo debatido nos encontros de especialistas em desenvolvimento rural é o planejamento para o desenvolvimento das áreas rurais. Nesse debate, discute-se a necessidade da presença de organizações administrativas intermediárias, formais ou informais, entre os municípios e os estados da federação e estão sendo incluídas na pauta de discussão, as definições e conceitos de território rural e desenvolvimento territorial. Essas organizações teriam a tarefa de construir conjuntamente projetos estratégicos de desenvolvimento com a participação da sociedade local, das diferentes instituições e das três esferas de poder Estatal.

Pensando na operacionalização do desenvolvimento territorial rural com a necessária consideração da participação social e das dinâmicas socioeconômicas de reprodução da agricultura familiar, Schneider e Tartaruga (2005) levantaram a questão da utilidade e da adequação da abordagem territorial para o estudo dos processos sociais contemporâneos. Na tentativa de responder a essa questão, defendem a possibilidade de se recorrer ao território como conceito e, ao mesmo tempo, aproveitar algumas su- 
gestões que vêm da abordagem territorial para realizar a análise de processos de mudança social, como um diálogo entre os conceitos analíticos da geografia econômica e o significado prático e instrumental das abordagens territoriais.

$\mathrm{Na}$ tentativa de estabelecer uma ponte hierárquica entre os significados de rural e local nos programas de desenvolvimento, Wanderley (2001) argumenta que os programas de desenvolvimento local, em vez de substituir o desenvolvimento rural, incorporam-no como parte integrante sem anular as particularidades. Acontece onde a diversidade e a proximidade são fontes de integração e cooperação e, ao mesmo tempo, de tensões e conflitos, configurando uma rede de relações recíprocas e complexas. A autora conclui afirmando que, se a vida local é o resultado do encontro entre o rural e o urbano, o desenvolvimento local, entendido como o processo de valorização do potencial econômico, social e cultural dessa sociedade, não pode supor o fim do rural, pois o desenvolvimento rural é parte integrante do desenvolvimento local (WANDERLEY, 2001).

Embora a definição do que seja exatamente desenvolvimento rural tenha variado ao longo do tempo, normalmente nenhuma das propostas conceituais deixa de destacar a melhoria do bem-estar das populações rurais como objetivo final do desenvolvimento rural. O conceito de desenvolvimento rural alterou-se ao longo do tempo, influenciado por diversas conjunturas e, principalmente, pelos novos condicionantes que o desenvolvimento macroeconômico e a vida social, gradualmente, impõem às famílias e às atividades rurais (NAVARRO, 2001).

Neste estudo, além de sua abrangência empírica territorial, entende-se desenvolvimento rural como sendo também um campo multidisciplinar de produção de conhecimento, muitas vezes, divergentes entre si (NAVARRO, 2001). Um exemplo disso é a quebra da fronteira setorial associada à noção de desenvolvimento rural que tratava como sinônimos o agrícola e o rural. Desde os anos 1990, o próprio significado do que é realmente o rural tem sido objeto de debate entre os pesquisadores e, em consequência disso, os seus conceitos tradicionais vêm sendo repensados. O que já é fruto desse debate é o abandono da identificação do rural como meramente agrícola e a pouca utilidade da dicotomia rural-urbano para as análises do desenvolvimento.

A partir daí, então, começaram a surgir estudos baseados na perspectiva territorial do desenvolvimento rural, na qual o local e o endógeno são características integrantes. Nesse ponto, é referência obrigatória o texto de Schejtman e Berdegué (2003), no qual os autores descrevem, de forma sistemática, a evolução do enfoque territorial e os conceitos e critérios operativos da abordagem centrada no desenvolvimento territorial rural (DTR). Esses autores definem DTR como um processo de transformação produtiva e institucional em um determinado espaço rural com a finalidade de reduzir a pobreza local. Além dessa permanente preocupação com a pobreza rural, reforçam o propósito de a produção se articular, de forma competitiva e sustentável, com a economia interna do território e com mercados externos dinâmicos. Além disso, segundo eles, o desenvolvimento institucional tem o propósito de estimular e facilitar a interação e a articulação dos atores locais, entre si e com os agentes externos relevantes. 
O turismo no espaço rural é definido como toda atividade turística existente nesse espaço, independente de estar ou não relacionada à produção agropecuária, considerando como uma estratégia para reduzir a pobreza rural e para gerar oportunidades de trabalho e renda para as famílias rurais. Então, a partir de um diagnóstico da dinâmica de um território rural, incluindo o panorama setorial da agricultura local e do potencial do turismo nesse espaço rural, podem ser definidos e avaliados os pontos fortes e fracos dessa nova atividade, sugerindo estratégias para o aproveitamento das oportunidades e potencialidades existentes no ambiente regional. Essa análise é necessária para uma reflexão sobre as possíveis alternativas e políticas públicas para o desenvolvimento dos territórios rurais.

Em diversos países europeus (como França, Portugal, Espanha e Irlanda), é muito comum que turistas sejam recebidos em estabelecimentos familiares rurais. Em Portugal, o turismo rural é caracterizado pelo acolhimento familiar e, por isso, classificado como "turismo de habitação". No entanto, o turismo no meio rural nesses países é difícil de servir de modelo para o turismo rural brasileiro porque a realidade rural, ambiental e social brasileira é muito diferente.

O Brasil tem um grande potencial turístico, com uma grande riqueza natural, representada por uma imensa costa marítima, rios, lagos, montanhas, fauna e flora, que indicam a vocação para o turismo, em todas as suas formas, mas é pouco explorado (EMBRATUR, 1994). No país, o turismo no espaço rural ainda tem diversos conceitos, sendo denominado de turismo de interior, agroturismo, turismo alternativo, de aventura, endógeno, turismo verde, ecoturismo, turismo de rotas, roteiros ou circuitos no meio rural, pesque-pague, entre outros.

De uma forma mais genérica, o "turismo no espaço rural" pode ser entendido como todas as formas turísticas de se visitar e conhecer os ambientes rurais, podendo ser resgatada e valorizada a cultura regional. O turismo no espaço rural tem como característica principal o fato de ser uma atividade capaz de gerar novas fontes de renda e emprego e integrar-se às atividades produtivas dos estabelecimentos rurais, como por exemplo, a produção leiteira ou de frutas, o cultivo de ervas medicinais ou a criação de animais silvestres. A questão essencial do "turismo no espaço rural" no Brasil é a busca pela preservação e conservação do ambiente rural e pelo desenvolvimento local sustentável, valorizando a cultura, o regionalismo e a história local.

\section{Turismo de experiência}

O turismo de experiência pode ser considerado como a resposta do turismo à tendência econômica atual que indica novas necessidades e valores de mercado. Tal tendência estaria sendo percebida e adequada por aqueles que desejam inovar na formação e comercialização de produtos.

O turismo de experiência é um conceito abrangente, que se posiciona além da 
ideia de consumo e que pode ser identificado como a satisfação das necessidades do consumidor, em uma operação viável e geradora de resultados. A oferta de experiências, na atividade turística implica muito menos considerar as pessoas "[...] pelos bens possuídos e cada vez mais pela confiança em suas histórias e pelos sentimentos demonstrados" (PANOSSO NETTO; GAETA, 2010, p. 14). O conceito do turismo de experiência indica, segundo os autores (2010, p. 44), "[...] um tipo de turismo que pretende marcar o turista de maneira profunda e positiva".

Detecta-se que a oferta de produtos aos turistas inclui atividades que contém atributos experienciais destinados à construção de estímulos (por meio da percepção, sensação, pensamento, ação, relacionamento), conforme palavras de Panosso Netto e Gaeta (2010, p. 140-143), que estejam associados, preferencialmente, à emoção. É possível identificar a experiência como uma sensação que está diretamente relacionada à sensação dos sentidos, indicando que "[...] a utilização de estratégias para enfatizar e aprimorar a vivência pelos cincos sentidos vem com o intuito de aumentar os processos cognitivos referentes ao evento encenado" (SOARES, 2009, p. 27). Como evento encenado, podemos caracterizar a transformação do ato turístico em um ato de experiência, no qual as ações visariam um aprofundamento do visitante no contexto da mesma.

Sob esse aspecto, Bahl (2003) indica ser o turismo, por excelência, uma atividade voltada para satisfazer necessidades do homem "em sua integridade física, mental e espiritual" (p. 7). Sob esse aspecto, Savastano (2008, p. 54-55) indica duas dimensões, pelas quais classificou as experiências de consumo. A primeira se refere ao relacionamento ativo ou passivo do consumidor na participação, criação ou desenvolvimento do estímulo. A segunda está relacionada à "maneira como os estímulos são percebidos ou consumidos, que pode ser por absorção ou por imersão".

A cocriação nas atividades, na qual os turistas podem escolher as experiências que querem vivenciar, também é mencionada por Morgan (2006), que as denomina de creative turismo, para as quais atribui "forma mais duradoura à experiência" aos visitantes, que passam a associar a vivência ao local em que ela foi proporcionada, resultando na incorporação da experiência ao local onde aconteceu.

As emoções estimuladas acionam a busca pela experiência, que, pela visão de Pannosso Netto e Gaeta (2010, p. 26), não se encontra "[...] um único conceito ou definição de experiência, mas podem-se descobrir vários desdobramentos conceituais", dependendo da filiação antropológica, filosófica ou psicológica a que esteja ligada. Cabe lembrar que a experiência tem caráter único e individual e "[...] que a mesma vivência de um grupo de indivíduos provocará diferentes experiências em cada um e ainda podem ocasionar diferentes sensações em épocas diversas de uma vida" (SOARES, 2009, p. 20).

No sentido de reconhecer a manutenção da competitividade dos empreendimentos turísticos por mais tempo, atribui-se parcela de responsabilidade para o cuidado que se tem com as categorias de experiências oferecidas para o público turista. É importante o entendimento da vivência contemporânea do que Panosso Netto e Gaeta $(2010$, p. 48) indicam ao dizer que "[...] tudo nos leva a crer que podemos estar vivendo, ou pelo menos tentando viver, a era da experiência". Tal ideia está ligada à percepção de que a sociedade atual busca novos horizontes, proporcionando o conhecimento e deslumbramento 
do novo, do simples, do singelo e do belo.

De acordo com Soares (2009), podem ser elencados como critérios do Turismo de Experiência:

- Surpresa - eventos, serviços ou produtos que saem da "rotina" e do "previsível" e superam as expectativas do indivíduo;

- Emoções únicas - experiências que ofereçam emoções dificilmente vivenciadas no dia a dia, que se tornam memoráveis, como voar de balão, pular de pára-quedas, etc;

- Exclusividade - a sensação de experimentar sensações únicas, sob medida para cada indivíduo, pois experiências serão sempre individuais;

- Uso dos cinco sentidos - ampliar as sensações por meio de todos os sentidos humanos proporciona melhor interação entre indivíduo, evento e meio;

- Interação - eventos, serviços e produtos que procuram maior interação e abrem portas para sensações e emoções diferenciadas;

- Despertar de sonhos e sentimentos - trabalhar os valores mentais, emocionais e imateriais em primeiro plano;

- Inclusão - Critério base para a formatação e o desenvolvimento de quaisquer produtos, serviços e eventos que garantam autonomia e independência de todos os indivíduos.

\section{A região turística Vale do Paranhana}

O Vale do Paranhana é uma região turística, localizada entre a Região Metropolitana e a Região das Hortênsias, composta por seis municípios: Três Coroas, Igrejinha, Taquara, Parobé, Riozinho e Rolante. A região é caracterizada pelo associativismo, pela religiosidade e pela celebração de festas familiares e comunitárias. Sua força econômica está centrada na indústria calçadista, na agricultura e na pecuária, desenvolvidas em pequenas propriedades familiares, mantendo costumes agrícolas tradicionais incorporados ao cotidiano. Predominam traços das culturas alemã e italiana, preservadas por meio das variadas festas étnicas e, inclusive, pelo uso corrente do idioma de origem dos antepassados. A presença indígena está representada na aldeia dos M’Byá Guarani, localizada no município de Riozinho.

O bioma Mata Atlântica é predominante na paisagem, com destaque para o município de Riozinho. O rio Paranhana é o local procurado para a prática de atividades de aventura, como a canoagem e o rafting. O templo budista tibetano Khadro Ling, em Três Coroas, aparece como outro importante atrativo.

A Região possui como característica a oferta turística diversificada, com empreendimentos ligados ao turismo rural, cultural, aventura, gastronômico e religioso, apresentando também uma forte tendência para atuar coletivamente em projetos que estimulem o desenvolvimento econômico e social da região. O Vale é dotado de um grande número de produtos e serviços voltados ao turismo, mas que precisavam inovar 
e organizar-se para um melhor desempenho e para a qualificação de setores ainda incipientes, como é o caso da oferta de entretenimento e lazer.

As Faculdades Integradas de Taquara - Faccat está situada no município de Taquara e possui como área de influência os municípios integrantes do Vale do Paranhana, além de municípios lindeiros da região como São Francisco de Paula, Sapiranga, Nova Hartz, Santo Antônio da Patrulha e outros. Composta por 18 cursos, entre eles o de Turismo - que possui sua ênfase no ecoturismo, turismo rural e turismo de aventura -, a Faccat tem apresentado um permanente interesse no envolvimento com as questões regionais.

Entre as atividades assumidas pela Faccat, a coordenação do Fórum Regional de Turismo pelo Curso de Turismo, tem sido um importante elo entre a comunidade e a academia, possibilitando um espaço amplo de integração entre o conhecimento empírico e a prática da atividade turística. Entre os projetos desenvolvidos pelo curso de Turismo na região, é possível elencar: Cidade no Campus, Salão Regional de Turismo, Feiras de agroprodutores, o Faccatchê, as reuniões de nivelamento, os cursos de extensão e, a partir do ano 2011, o Projeto Vale das Experiências.

\section{O Projeto Vale das Experiências}

O projeto intitulado Vale das Experiências busca a organização do território formado pelos municípios distribuídos na Região Turística Vale do Paranhana, tendo o Curso de Turismo da Faccat como o gerenciador do projeto. Esse projeto pretende criar uma rede de cooperação entre empreendimentos e destinos, localizados nos municípios integrantes, partindo da participação do poder público e privado, na gestão de experiências diferenciadas a serem ofertadas ao turista.

Como objetivo do projeto, é possível identificar:

A estruturação e implementação da oferta turística de acordo com os conceitos inovadores do Turismo de Experiência, bem como a integração de mercado através da geração de uma rede de cooperação. As macroações desta proposta visam a diversificação da oferta turística, a ampliação do consumo turístico e o aumento da geração de emprego e renda na região (FACULDADES INTEGRADAS DE TAQUARA, 2011).

Para a execução de tal objetivo, foram contatadas as micro e as pequenas empresas da cadeia de valor do turismo, destacando-se os segmentos de hotelaria, restaurantes e similares, empreendimentos turísticos e serviços afins. A participação no projeto estava condicionada a uma análise prévia de roteiros, dos produtos turísticos e dos serviços já existentes na região. A organização do projeto seguiu passos pré-definidos e foi discutida em reunião do Fórum Regional de Turismo do Vale do Paranhana, governança local do turismo e coordenada pelo Curso de Turismo da Faccat.

As principais ações definidas pelo projeto envolvem práticas que conduzam à formação de uma rede de cooperação, conectada entre os empreendimentos envolvidos no planejamento do Vale das Experiências, bem como a inovação de produtos e serviços existentes, dentro do conceito desenvolvido. As ações também procuram qualificar a oferta de entretenimento e lazer, capacitar os profissionais envolvidos nos segmentos 
diversos e, assim, criar uma estrutura capaz de promover a sustentabilidade do projeto, a sua ampliação e a visibilidade do produto.

O Projeto, de acordo com as Faculdades Integradas de Taquara (2011), foi organizado em seis etapas, assim distribuídas:

Etapa I: reconhecimento da situação atual. Tratam-se de ações iniciais de encaminhamento do projeto, de difusão do conceito, de realização do curso de turismo de experiência, seleção de bolsistas e alinhamento da equipe. Para a execução das primeiras ações, foram realizadas reuniões junto aos empreendedores e aos possíveis integrantes do projeto, bem como com as instâncias locais como prefeituras, associação de municípios e demais interessados. A maneira definida para uma melhor difusão do conceito foi a realização do curso de extensão de Turismo de Experiência. O curso foi realizado pela Faccat no ano de 2011, com a grade curricular conforme o Quadro 1.

\begin{tabular}{|l|c|}
\hline \multicolumn{1}{|c|}{ Disciplina } & Carga Horária \\
\hline Turismo e Experiência & 12 horas \\
\hline Antropologia da Experiência & 08 horas \\
\hline Gestão da Experiência & 12 horas \\
\hline Natureza como experiência & 12 horas \\
\hline Experiência cultural & 12 horas \\
\hline Experiência e Empresas Turísticas & 12 horas \\
\hline Marketing da Experiência & 08 horas \\
\hline Redes Sociais e Experiência & 08 horas \\
\hline Formatação de Projetos & 08 horas \\
\hline
\end{tabular}

Quadro 1: Disciplinas do Curso de Turismo de Experiência Fonte: Faculdades Integradas de Taquara (2011)

O curso contou com 32 alunos, indicados pelos municípios que integram a Associação dos Municípios do Vale do Paranhana, além de empresários de Novo Hamburgo e São Francisco de Paula, municípios lindeiros à região. Após a realização do curso, foram selecionados dois bolsistas, alunos do curso de turismo da Faccat, para atuarem diretamente com os empreendimentos participantes.

Coube aos bolsistas integrantes do Laboratório de Turismo do curso, em parceria com os professores, definir e aplicar a metodologia de análise dos empreendimentos para a formatação dos produtos de experiência junto às propriedades e aos empreendimentos que iriam compor a primeira etapa do projeto

Etapa II: trabalhando o conceito. A segunda etapa do projeto contou com a realização do Seminário de Turismo do Vale do Paranhana - Construindo o Vale das Experiências, realizado em setembro de 2011.

O conceito foi sendo trabalhado junto à comunidade regional, nas reuniões de integração de conhecimentos sobre o desenrolar das atividades de desenvolvimento 
técnico e operacional do Vale das Experiências, voltadas a empreendedores do projeto, entidades e instâncias do governo, ampliadas a setores importantes do mercado para a compreensão e a sensibilização para o necessário suporte às ações do projeto.

Etapa III: desenvolvendo os produtos. Foram realizadas visitas técnicas pelos bolsistas e pelos professores envolvidos no projeto com o objetivo de proporcionar aos empreendedores participantes o contato com um modelo de negócio fundamentado no conceito do Turismo de Experiência, de modo a ajudá-los com a formatação do produto.

Assim, a primeira etapa da visita técnica incluía a assinatura do termo de adesão ao projeto. Na sequência, ocorreram as visitas técnicas, objetivando o cruzamento de dados já existentes nos empreendimentos e a proposta de experiência a ser desenvolvida, formatando uma Tabela Matriz de Relacionamento e, posteriormente, a Tabela de Experiência.

A Tabela Matriz de Relacionamento tem por base os dados coletados no diagnóstico empresarial e busca associar a empresa integrante do projeto a serviços por ela oferecidos e a oportunidade de agregar serviços/produtos em uma visão de promoção da economia criativa. A Tabela de Experiência compreende um exercício à dinâmica do diferencial competitivo, por meio da relação entre necessidades humanas, expectativas dos turistas em relação ao destino e possíveis serviços de experiência a serem oferecidos pelos empreendimentos integrantes do projeto e relacionadas pela equipe técnica do projeto.

Etapa IV: ampliando a rede de cooperação. A quarta etapa do projeto visa ao desenvolvimento de uma rede de cooperação entre os empreendimentos participantes e possíveis parcerias novas. A ideia inicial parte do desenvolvimento do site do Vale das Experiências, contendo informações do projeto e dos empreendimentos selecionados. Para tanto, foi desenvolvida a logomarca do projeto pela Agência de Comunicação da Faccat - AGECOM.

Etapa V: gestão mercadológica. Ainda não teve início

Etapa VI: sustentabilidade, acompanhamento e avaliação. Ainda não teve início.

\section{Considerações finais}

Alguns territórios rurais, como a região do Vale do Paranhana, podem aproveitar as oportunidades decorrentes da dinâmica global de desenvolvimento, combinando eficientemente o desenvolvimento de suas potencialidades locais (recursos ambientais e turísticos, agricultura familiar, instituições, etc.) com o aproveitamento eficaz das oportunidades externas. Esse parece ser o caso representado pela possibilidade de desenvolvimento do turismo na região Vale do Paranhana, aproveitando o potencial local dos seus recursos e as oportunidades dos mercados turísticos regionais.

A partir de um diagnóstico da dinâmica do território rural, incluindo o panorama setorial da agricultura local e do potencial do turismo regional, espera-se que possam ser definidos os pontos fortes e avaliados os pontos fracos dessa nova atividade na re- 
gião. Com isso, poderão ser sugeridas as estratégias para o aproveitamento das oportunidades de mercado e potencialidades turísticas existentes no ambiente local.

O Projeto Vale das Experiências continuará sendo desenvolvido e organizado no território formado pelos municípios da região Vale do Paranhana. O projeto pretende criar uma rede de cooperação entre empreendimentos e destinos, localizados nos municípios integrantes da região, contando com a participação dos governos estadual e municipais, dos atores sociais locais e das empresas da região, na prospecção e gestão de experiências diferenciadas a serem ofertadas aos turistas que visitam ou que vierem a visitar a região.

\section{Referências}

ABRAMOVAY, Ricardo. Funções e medidas da ruralidade no desenvolvimento contemporâneo. Texto para Discussão n 702. Rio de Janeiro: IPEA, 2000.

ALBAGLI, Sarita; MACIEL, Maria Lucia. Pequena empresa: cooperação e desenvolvimento local. Rio de Janeiro: Relume Dumará; UFRJ, Instituto de Economia, 2003.

BAHL, Miguel (Org.). Perspectivas do Turismo na Sociedade Pós-Industrial. São Paulo: Roca, 2003.

BASILE E.; CECCHI C. La trasformazione post-industriale della campagna.

Dall'agricoltura ai sistemi locali rurali. Torino: Rosenberg \& Sellier. 2001.

EMBRATUR. Diretrizes para uma Política Nacional de Ecoturismo. Brasília, 1994.

FACULDADES INTEGRADAS DE TAQUARA. Curso de Turismo. Projeto Vale das

Experiências. Taquara, 2011.

FEGER, José Elmar et al. Regionalização do turismo: uma análise espacial do Arranjo Produtivo Local Rota da Amizade. Observatório de Inovação do Turismo - Revista Acadêmica, FGV, Rio de Janeiro, v. 3. n. 4, 2008.

MALDONADO, Carlos. O Turismo rural na América Latina: gênesis, características e políticas. In: BARTHOLO, Roberto; SANSOLO, Davis Gruber; BURSZTYN, Ivan (Orgs.). Turismo de base comunitária: diversidade de olhares e experiências brasileiras. Rio de Janeiro: Letra e Imagem, 2010.

MORAES, Jorge Luiz Amaral de. Dinâmicas Sócio-Econômicas de Desenvolvimento dos Territórios Rurais: Os Sistemas Produtivos Localizados (SPLs) da Região Vale do Rio Pardo - RS. 2008. Tese (Doutorado em Desenvolvimento Rural) - Universidade Federal do Rio Grande do Sul, Porto Alegre, 2008.

MORGAN, M. Festival Spaces and the Visitor Experience. In: CASADO-DIAZ, M., EVERETT, S.; WILSON, J. (Eds.). Social and Cultural Change: Making Space(s) for Leisure and Tourism. Eastbourne, UK: Lesiure Studies Association, 2006.

NAVARRO, Zander. Desenvolvimento Rural no Brasil: os limites do passado e os caminhos do futuro. Revista Estudos Avançados, São Paulo, v. 16, n. 43, 2001. 
PANOSSO NETTO, Alexandre, GAETA, Cecília (Orgs.). Turismo de Experiência. São Paulo: Senac, 2010.

RIO GRANDE DO SUL. Secretaria de Turismo do Estado. Plano de Desenvolvimento do Turismo do Rio Grande do Sul. 2012-2015 / FGV Projetos - Rio de Janeiro: FGV Projetos, 2012.

SAVASTANO, M. O produto de Entretenimento. In: COBRA, Marcos (Org.). Marketing do Entretenimento. São Paulo: Senac, 2008.

SCHEJTMAN, A.; BERDEGUÉ, J. Desarrollo Territorial Rural. Santiago: RIMISP, 2003.

SCHNEIDER, S.; TARTARUGA, I. G. P. Do Território Geográfico à Abordagem Territorial do Desenvolvimento Rural. Jornadas de Intercambio y Discusión: El Desarrollo Rural en su Perspectiva Institucional y Territorial. Flacso, Argentina, Universidad de Buenos Aires/Conicet. 23-24 de junho de 2005.

SOARES, Tamara. Características do Turismo de Experiência: Estudos de Caso em Belo Horizonte e Sabará sobre Inovação e Diversidade na Valorização dos Clientes. 2009. 99 p. Dissertação (Mestrado em Geografia) - Universidade Federal de Minas Gerais, Minas Gerais, 2009. Disponível em: <http://biblioteca.igc.ufmg.br/monografias/ Turismo/2009/Tamara\%20Coelho\%20Soares/tcc3.pdf>. Acesso em: 20 dez. 2012.

VÁZQUEZ-BARQUERO, Antonio. Desenvolvimento Endógeno em Tempos de Globalização. Porto Alegre: FEE/UFRGS, 2001.

WANDERLEY, M. N. B. A ruralidade no Brasil moderno; por um pacto social pelo desenvolvimento rural. In: GIARRACCA, Norma (Org.). ¿Una nueva ruralidad en América Latina? Buenos Aires: CLACSO, 2001. 